\title{
Advancing postpartum hemorrhage care (APPHC): Partnership approach and portfolio overview
}

Breakthrough RESEARCH

USAID's Health Evaluation and Applied Research Development

Follow this and additional works at: https://knowledgecommons.popcouncil.org/departments_sbsr-rh

Part of the Health Communication Commons, and the Public Health Commons

How does access to this work benefit you? Let us know!

\section{Recommended Citation}

Breakthrough RESEARCH and USAID's Health Evaluation and Applied Research Development. 2021.

"Advancing postpartum hemorrhage care (APPHC): Partnership approach and portfolio overview," APPHC Programmatic Research Brief. Washington, DC: Population Council and URC. 


\section{Advancing Postpartum Hemorrhage Care (APPHC): Partnership Approach and Portfolio Overview}

Nearly one-quarter of all maternal deaths are associated with postpartum hemorrhage (PPH) globally. $\mathrm{PPH}$ remains the leading cause of maternal death in most low-income countries, requiring additional research on prevention and treatment options. In response to this challenge, U. S. Agency for International Development (USAID) has complemented its longstanding efforts to accelerate reductions in maternal deaths with a one-time catalytic investment in Malawi and Madagascar called Advancing Postpartum Hemorrhage Care (APPHC). This brief presents the partnership, approach and expected results of the APPHC investment. Accompanying briefs provide more detail on project activities by country. For more details, visit our webpage: https://www.respectfulcareresources.com/apphc.

The objective of the APPHC investment is to generate and test solutions that address key barriers to PPH prevention, detection, and treatment. USAID invested in both the Breakthrough RESEARCH and the Health Evaluation and Applied Research Development (HEARD) Projects implemented by Population Council and University Research Co., LLC, respectively. Joint objectives are achieved by:

1. Establishing and sustaining an inclusive APPHC partnership that identifies PPH-related health priorities;

2. Advancing the woman-centered maternity care and social behavior change agendas through an implementation science approach;

3. Implementing a portfolio of activities reflective of local priorities and changing contexts;

4. Reinforcing effective stakeholder communication, knowledge management, and dissemination locally, regionally, and globally; and,

5. Enabling implementation science advocacy and capacity development among partners throughout the process.

\section{CHALLENGES TO ADDRESSING}

POSTPARTUM HEMORRHAGE IN MALAWI AND MADAGASCAR

Findings from APPHC scoping reports, formative research, and consultations with stakehold-

ers identified similar types of challenges in

Madagascar and Malawi despite varying levels of health system development, facility delivery rates (44\% Madagascar, 90\% in Malawi) and different sociocultural and political contexts. Stakeholders highlighted PPH prevention, detection and management challenges related to commodity availability, limited human resources and low provider motivation, weak infrastructure, and a lack of functioning referral systems.

\section{The Opportunity}

The APPHC Partnership's agenda and portfolio of activities build on and leverage the two major health systems bilateral projects funded by USAID: Organized Network of Services for Everyone (ONSE) in Malawi and Accessible Continuum of Care and Essential Services Sustained (ACCESS) in Madagascar. These large implementation investments, with existing collaborations with Ministries of Health and other key gatekeepers and decision-makers, offer platforms ripe for embedding APPHC activities. The APPHC Partnership seeks to inform ACCESS and ONSE, to the extent possible, along with current and future USAID investments, and respond to additional key decision-makers in each country.
POPULATION COUNCIL

Ideas. Evidence. Impact.

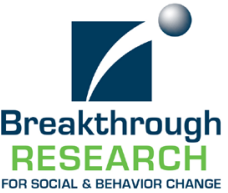


While APPHC activities are most relevant and responsive to Malawi and Madagascar needs and stakeholder priorities, the learning experience is intended to be leveraged and applied to other contexts, which is why we strive for strategic engagement of regional and global platforms as well.

\section{APPHC Partnership \& Structure}

APPHC is led by two complementary global research projects-Breakthrough RESEARCH, which focuses on social and behavior change (SBC) research and evaluation, and the HEARD project which advances implementation science strategies for maternal and newborn child health. The Partnership is collaboratively co-managed and leverages each project's respective comparative strengths to achieve the objectives. Breakthrough RESEARCH draws on years of expertise in rigorous and innovative approaches to SBC programming design, research and evaluation; HEARD brings extensive, unique expertise as a research systems integrator, consortium builder, and accelerator of the evidence-to-use pathway. Both projects leverage their significant network of subject-matter and methodological expertise.

Through partnership and collaboration with USAID missions and their respective country-level bilateral projects, ACCESS
(Madagascar) and ONSE (Malawi), local and global research institutions, local policy and advocacy leaders, and Ministries of Health, the APPHC Partnership harnesses the core collaborative principles of an implementation science approach.

\section{Implementation Science}

\section{Approach and Theory of Change}

\begin{abstract}
The Breakthrough RESEARCH and HEARD projects are committed to leveraging rigorous evidence to inform SBC and other approaches that can lead to improved health and development outcomes for women and newborns. For this reason, the APPHC activity takes an implementation science (IS) approach, underscoring the need to generate research that is directly applicable to PPH policy, programs, and service delivery needs in our country contexts: Malawi and Madagascar (and beyond). This approach requires engagement with a range of stakeholders to build learning agenda consensus, raise demand for evidence, and lay the groundwork for practical application of evidence-based recommendations. APPHC partners view the process of identifying priorities and producing evidence as a catalyst for change.
\end{abstract}

FIGURE 1 VISUAL DEPICTION OF THE APPHC ACTIVITY PARTNERSHIP

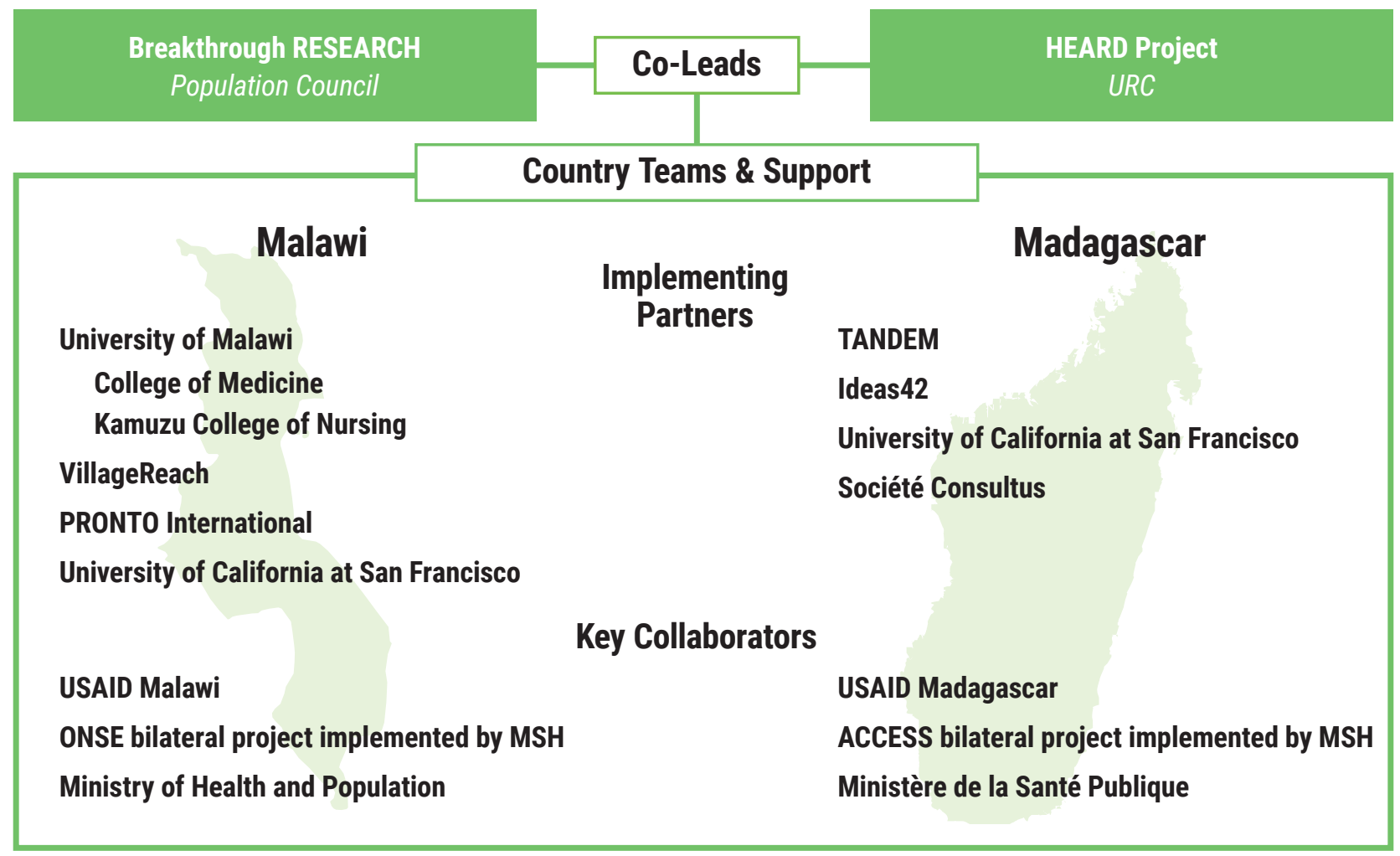




\section{IMPLEMENTATION SCIENCE}

USAID's Global Health Research \& Development

Mission is "to support collaborative research from

the local to the global level, generating evidence

on interventions, policies, approaches, and

technologies that increase the impact of health

programs globally."

To achieve this, implementation science is a key

area of focus as an approach "to identify, generate,

and apply evidence to influence the adoption,

implementation, and health impact at scale

of priority life-saving health and development

interventions."

(https://www.usaid.gov/sites/default/files/documents/1864/

USAIDGlobalHealthRDStrategy_2017-2022.pdf)

\section{The APPHC Partnership Theory of Change}

IF the APPHC Partnership:

1. Addresses relevant and responsive local stakeholder priorities;

AND

2. Embeds activities in local implementation and policy platforms;

\section{AND}

3. Leverages and strengthens diverse partnership capacities in SBC and IS;

\section{AND}

4. Strategically engages stakeholders through continuous communication and dissemination of findings from IS and $\mathrm{SBC}$ research activities;

\section{AND}

5. Documents and adapts to changing contexts (e.g., COVID-19);

\section{AND}

6. Data analysis and interpretation is robust, well-articulated and packaged;

THEN the APPHC partnership effectively accelerate the use of evidence to improve high quality, respectful maternity service provision.

\section{Implementing an IS Approach}

To execute an implementation science approach and enable the theory of change in practice, a deliberate set of strategies is required. The strategic processes listed below bolster the strategic, technical, financial, and administrative capacities needed for success.

Establish a strategic partnership: engaging partners with regional policy and practice platforms that can inform and benefit from the study and partnership with local research institutions with maternal health linkages to further develop their implementation science capacity and ensure questions are relevant and findings are responsive to local context.

$\checkmark$ Facilitate consultative priority development: while more time intensive, a consultative process involving stakeholder meetings and discussion allows for a deeper understanding of priorities, perspectives and opportunity to identify priority provider behavior change implementation research questions.

$\checkmark$ Continuous meaningful engagement of stakeholders to share experience and results: facilitating buy-in and raising demand for results among key decision-makers is critical to accelerating translation of findings into action. This is achieved through participation in country working groups, convenings hosted by the East Central Southern Africa Health Community and global conferences such as the PPH Community of Practice.

$\checkmark$ Effectively package and share evidence: $A P P H C$ will translate existing and newly generated evidence into audience-tailored, action-oriented messages that are packaged in user-friendly language and accessible print and digital formats. These products will be shared widely through well-established knowledge management platforms and may include the following: briefs and factsheets; data visualization techniques and infographics; videos and multimedia presentations; and in-person and virtual learning events.

Leverage external strategic guidance: to reinforce transparency and objective outside guidance, the Partnership convenes a technical advisory group (TAG). The TAG provides guidance on how best to link and leverage the APPHC partnership activities and sustain established learning processes.

$\checkmark$ Provide "research systems integration": given the complexity of the Partnership, the diverse cultural and language differences and contexts in which we are implementing, the APPHC Core Team functions as the "Research Systems Integrator" (RSI) or conductor of the Partnership. This function requires identifying and coordinating technical, financial, and administrative capacity from within and beyond the Partnership as needed 
to implement the portfolio. The RSI role is critical for ensuring: a strategy and partners are in place; positive relationships and a coordinated, well-communicated effort; enhanced partner capacity; sound financial and administrative processes and compliance; and timely and high-quality deliverables.

\section{APPHC Partnership Portfolio Overview}

After an extensive consultative process, the APPHC partnership portfolio of activities was initially defined in 2019. With the emergence of COVID-19, review and adaptation of the original portfolio was needed, including identifying new opportunities for learning. The APPHC portfolio consists of two "groups" of activities implemented concurrently across Madagascar and Malawi: (1) Implementation research studies that center on the testing/studying of approaches (requiring relatively longer timelines) and (2) activities that center on communication, use of real-time data/evidence for decision-making, rapid case studies, and process documentation (relatively shorter but ongoing). The portfolio addresses multiple domains within health systems, appreciating effective PPH prevention, detection, and management requires a functional system; investigates innovative/promising approaches and how they address system and behavior change issues related to PPH in real life contexts; and generates recommendations on how to deliver or improve implementation and sustainability of approaches/interventions.

As depicted in the graphic below, the APPHC portfolio contributes to the strengthening of systems to improve $\mathrm{PPH}$ prevention and treatment through addressing key domains drawn from the Maternal and Child Survival Program PPH Framework. For more details, visit the APPHC webpage and country-specific activity briefs.

\section{FIGURE 2 PORTFOLIO SUMMARY}

\section{STRENGTHENING SYSTEMS TO IMPROVE PPH PREVENTION AND TREATMENT \\ (1)}

8.

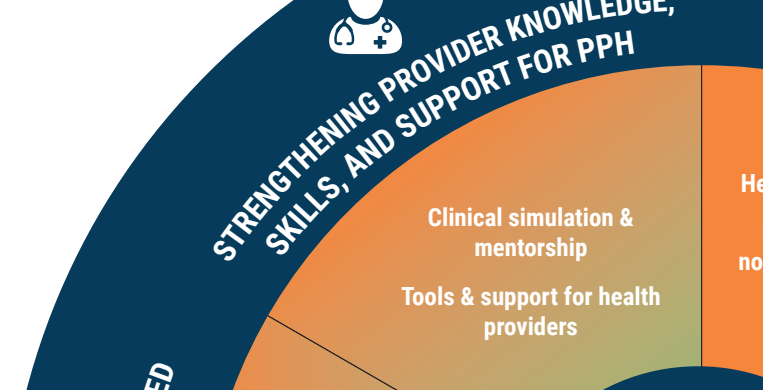

.

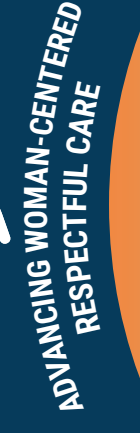

Improved provider

support \&

mentorship

Provider vulnerabilities mitigated

Companionship at birth

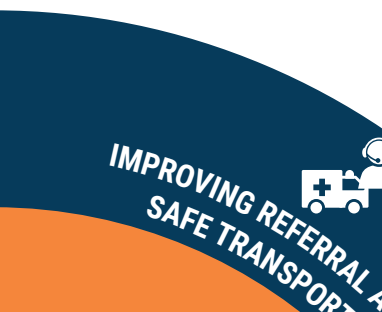

Health Hotline for referral

Maintenance \& use of

non-pneumatic anti-shock

garments (NASG)

Use of maternity waiting homes

Better access, provision, \& consistency of response to PPH

More confident, motivated, \& competent providers

More competent teams

providing timely, appropriate, \& effective PPH care

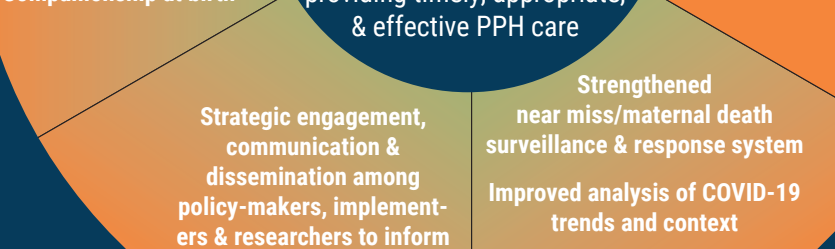

policy-makers, implement-
ers \& researchers to inform

- improvements in

( $1 / P_{0}$ policy \& strategy

Process documente

Assessment of availability \& access to blood

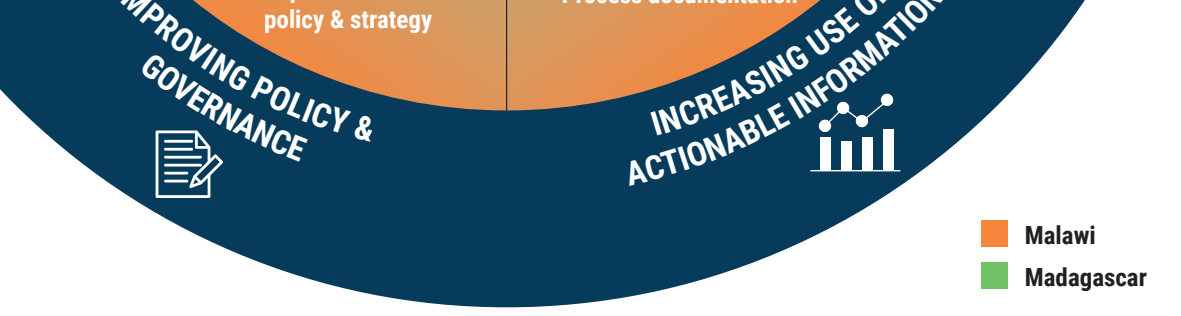




\section{Looking Forward}

HEARD and Breakthrough RESEARCH projects successfully co-lead a partnership embedded in two USAID bilateral investments in two countries. The stakeholder-engaged approach has increased demand for and relevance of activities among local decision-makers. The diversity of portfolio activities, in terms of health system domains and methods for addressing PPH, is yielding a breadth of lessons learned and filling critical evidence gaps (e.g., in the area of provider behavior change). Strong partnership allowed for adaptation to the COVID-19 pandemic and the ability to incorporate new opportunities for learning and partner support. In addition to the generation of new evidence, information and tools, our concerted effort to invest in process documentation will inform how to replicate or draw on lessons learned from the APPHC partner collaboration model for future USAID (or other) investments.

The APPHC Partnership looks forward to dissemination and communication of recommendations to inform change during the next six months-and to the possibility of exploring new opportunities to strengthen access to high quality respectful maternity care in low- and middle-income country contexts.
This work is part of the Advancing Postpartum Hemorrhage Care (APPHC) partnership supported by USAID and led by the Breakthrough RESEARCH Project and the Health Evaluation and Applied Research Development (HEARD) Project. The APPHC partnership generates and tests solutions to address key implementation barriers for PPH prevention and treatment and contributes to the effective implementation of interventions, strategies, and innovations for PPH in Madagascar and Malawi.

https://www.respectfulcareresources.com/apphc

\section{Suggested citation:}

Breakthrough RESEARCH and USAID's Health Evaluation and Applied Research Development. 2021. "Advancements in postpartum hemorrhage care (APPHC): Partnership approach and portfolio overview," APPHC Programmatic Research Brief. Washington DC: Population Council and URC.

C 2021 The Population Council and URC. All rights reserved.
Breakthrough RESEARCH

Population Council

4301 Connecticut Ave., NW

Suite 280

Washington, DC 20008

+12022379400

breakthroughactionandresearch.org

BreakthroughResearch@popcouncil.org
USAID's Health Evaluation and Applied Research Development

URC

5404 Wisconsin Ave

Suite 800

Chevy Chase, MD 20815

www.heardproject.org

heard@urc-chs.com

\section{USAID MAIIIIII) FROM THE AMERICAN PEOPLE}

This document is made possible by the generous support of the American people through the United States Agency for International Development (USAID) under cooperative agreements Breakthrough RESEARCH (AID-OAA-A-17-00018) and USAID's Health Evaluation and Applied Research Development Project (HEARD) (AID-OAA-A-17-00002). The contents of this document are the sole responsibility of Breakthrough RESEARCH, Population Council, and University Research Co., LLC and do not necessarily reflect the views of USAID or the United States Government.

USAID'S HEALTH EVALUATION AND APPLIED RESEARCH DEVELOPMENT (HEARD) PROJECT

USAID's Health Evaluation and Applied Research Development (HEARD) project leverages a global partnership of more than 30 institutions to generate, synthesize, and use evidence to improve the implementation of policies and programs related to USAID priority areas, and crucial for improving health and development in low and middle-income countries.

\section{- POPULATION COUNCIL}

Ideas. Evidence. Impact.

\section{Breakthrough RESEARCH FOR SOCIAL \& BEHAVIOR CHANGE}

Breakthrough RESEARCH catalyzes SBC by conducting state-of-the-art research and evaluation and promoting evidence-based solutions to improve health and development programs around the world. Breakthrough RESEARCH is a consortium led by the Population Council in partnership with Avenir Health, ideas42, Institute for Reproductive Health at Georgetown University, Population Reference Bureau, and Tulane University. 